THE ECLIPSE OF JANUARY 1, I889. ${ }^{1}$

DURING the year 1889 two total eclipses occurred, one on January I, and the other on December 21. The present report refers to the former, and contains a detailed account of all the work that was undertaken by those who formed hamlet called Norman, on the north branch of the Southern Pacific Railway, about I 30 miles from San Francisco. Situated south was Mount Shasta, and so nearly was it in the meridian that, as Prof. Pritchett says, "its snow-capped cone was used for instrumental adjustment without appreciable error."

The equipment as regards instruments included an equatorial

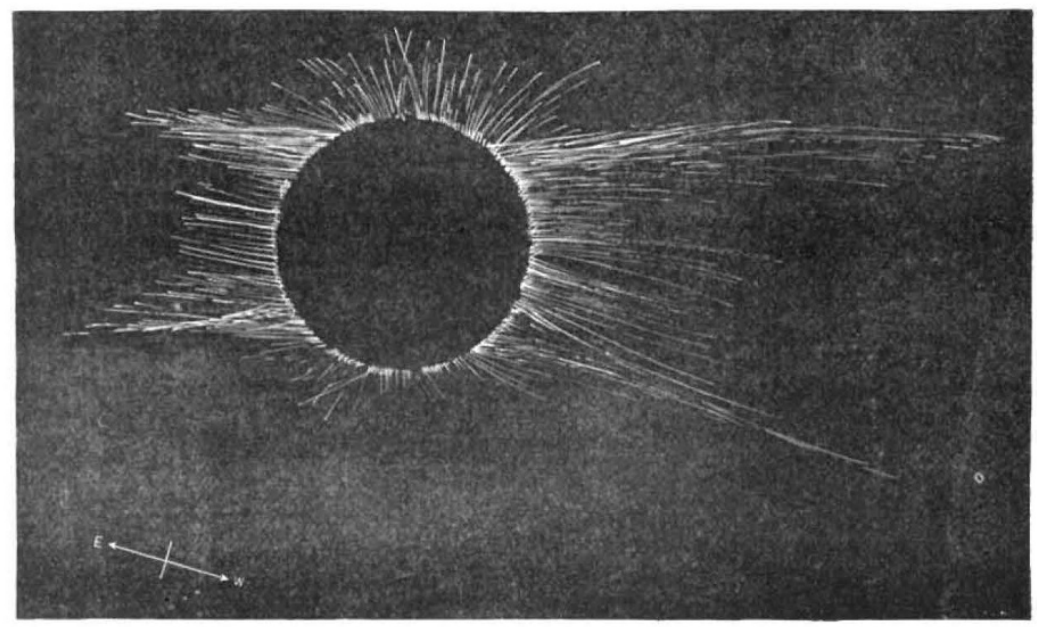

FiG. x. -Prof. Engler's sketch of corona, 188g.

the party from the Washington University Observatory. Owing to the proximity of this Observatory to the path of totality, the chance of observing the eclipse was made the most of, but was only made possible, as Prof. Pritchett says, "by the kindness of Government officials and others in lending instruments, and by the liberality of friends of the University in subscribing money for the necessary expenses." camera, with one of Dallmeyer's patent portrait and group lenses, size No. 8.D., having a clear aperture of $60^{\circ}$ inches, and an equivalent focal length of $37^{\circ} 9$ inches. Owing to the difficulty of keeping the tube light-tight, to prevent the fogging of the plates, an automatic shutter had to be used, the largest obtain. able cutting the aperture down to 4.5 inches. Two telescopes were also employed-one being a 4 -inch Clark's refractor

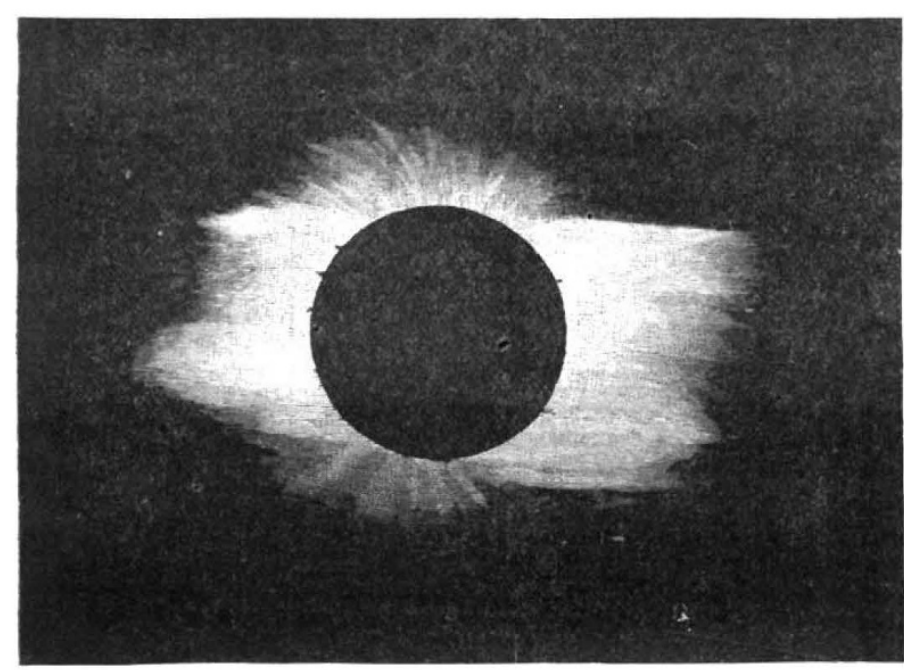

FIG. 2.-Composite photograph of corona, 1889 .

The party consisted of Profs. H. S. Pritchett, Director of the Observatory, F. E. Nipher, and E. A. Engler, together with Prof. C. M. Charroppin, of the St. Louis University Observatory, and Prof. Señor Valle, of the National Observatory of Mexico.

The spot fixed upon for observing the eclipse was a small

${ }^{2}$ Report of the Washington University Eclipse Party. NO. I I 56, VOL. 45]

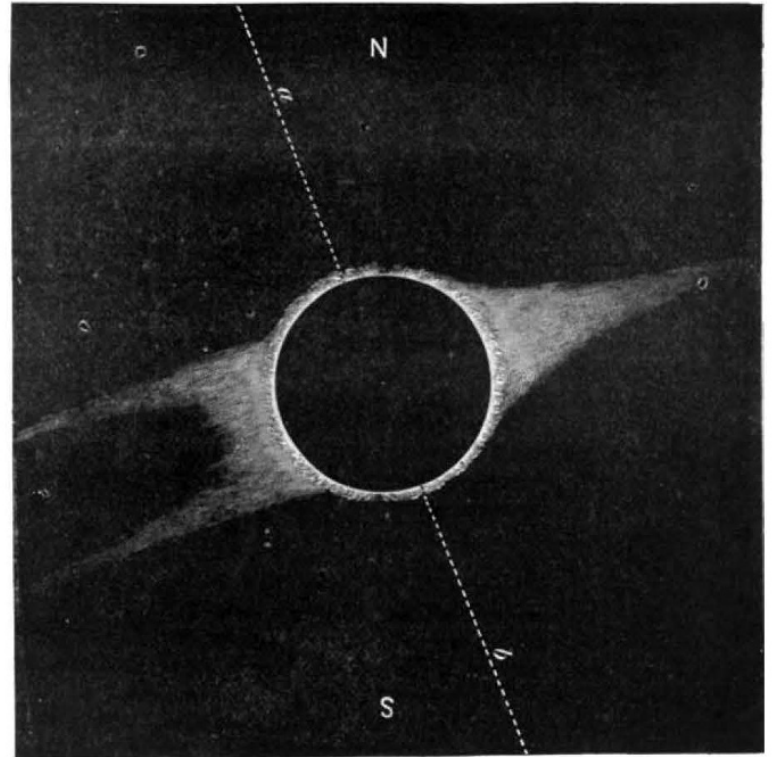

FIG. 3.-Lockyer's sketch of corona, 1878 .

equatorially mounted, with magnifying powers from 50 to 400 ; the other a French instrument with an aperture of 3 inches, and an altitude and azimuth mounting.

Although the first contact was lost through the formation of a heavy bank of clouds, the sky near the sun soon afterwards became clear, and "the seeing was excellent and the inage of the sun was sharp and distinct." In all the six negatives 
obtained the definition was found to be very good, but on account of the difference in the lengths of the exposures given to the several plates, some of them proved to be rather thin. The task of developing them was imposed upon Prof. Charroppin, who gives a brief, interesting account of the process of their development. The observations of the times of contact and the study of the corona were undertaken by Prof. Engler, with the aid of the French instrument. Although only two contacts were recorded (the second and the fourth), he made no attempt at the third, owing to the short space of time at his disposal for observing and sketching the corona. The drawing which he made is produced (together with the other photographs) in this report, and tallies, when compared with them, in nearly all respects, with the exception of the two equatorial streamers on the west side, that appear to extend further westward than those recorded in the photographs.

It is interesting to note in the illustrations the great similarity between the corona observed in this eclipse and that of the year 1878 , in which year the sun-spot disturbances were at the minimum. Figs. 1 and 2 represent the corona of the year 1889 , the former being a drawing by Prof. Engler, the same as the one previously mentioned, while the latter is the integrated result of the examination of all the photographic plates, and "does not represent the corona as seen by the eye, nor as shown on any one of the negatives, but is a combination of all that could be found in the negatives."

The next illustration (Fig. 3 ) is a sketch of the corona made by Mr. Lockyer during the eclipse of 1878 (NATURE, vol. xviii. p. 457), and when compared with the above figures fully bears out the idea that at the several periods throughout a sunspot cycle there corresponds in the corona a like period, which is apparent to us only in the changes of form undergone by the equatorial and polar streamers, and this only at the time of eclipses.

The following brief extracts, which we give in the observers' own words, will show how the descriptions of the appearance of the corona resembled one another in all the main points. With regard to the structure at the north and south poles, Mr. Lockyer says (NATURE, vol. xviii. p. 457) :-

"I had a magnificent view of the corona with a power of 50 on my $3 \frac{3}{4}$-inch Cooke, and saw exquisite structure at the north and south points, Curves of contrary flexure started thence, and turned over, and blended with the rest of the corona, which was entirely structureless and cloudlike; the filamentous tracery, which in India I observed till three minutes after totality, had indeed almost gone. Prof. Bass, however, tells me that by confining his attention to the same point for nearly the whole time of totality, the structure came out and seemed to pulsate like an aurora."

Prof. Pritchett's account is almost the same, word for word, as may be seen from the following extract :-

"I was particularly struck," he says, "with the brilliant appearance in the telescope of the filaments at the north and south limbs of the sun. They seemed radial at the poles, but gradually bending over and merging into the equatorial streamers in passing from the pole to the equator. I could not resist the impression that these filaments pulsated.'

From the above it will be seen that the appearances at the pole for both years were very similar; and with regard to the equatorial streamers also, their notes show that the characteristic features of each coincided in almost all particulars. Owing to the fact of the minimum spot period occurring at both eclipses, the above results strengthen very considerably the hypothesis connecting the spot cycle with the corona.

In addition to Prof. Engler's drawing mentioned above, Señor Valle also made some eye observations of the coronal streamers. The method he adopted was similar to that employed by Prof. Newton in 1878, and consisted in placing a screen in such a position that during totality the moon and the brighter corona were cut off. The photo-engraving of the drawing shows an extension of the equatorial streamers to about a distance of three solar diameters, while the polar regions were described as of a curved luminous filamentary contraction.

Before concluding, we must not forget to mention the admirable artotype reproductions, at the end of the report, of all the negatives: as they are arranged in the order of the times of exposure, they show well the progressive increase of detail on the outer part of the corona as the exposure was lengthened.

\section{SIMPLE PROOF OF EUCLID II. 9 AND Io.}

THE following proof of Euclid II., 9 and Io, believed to be new, due to Miss Hilda Hudson, was communicated to the London Mathematical Society at their last meeting.

$\mathrm{AB}$ is bisected in $\mathrm{C}$ and divided unequally in $\mathrm{D}$ either internally (II. 9) or externally (II. IO). It is required to prove that the sum of the squares on $A D$ and $D B$ is equal to twice the sum of the squares on $A C$ and $C D$.

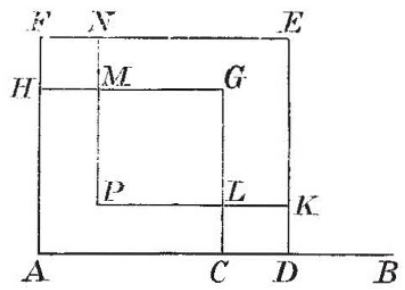

II.9.

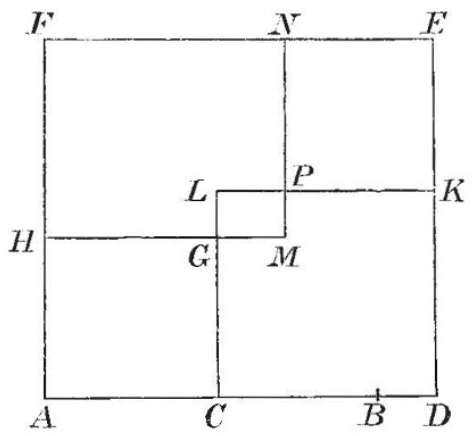

71.10 .

On $\mathrm{AD}, \mathrm{AC}, \mathrm{CD}$, describe the squares $\mathrm{ADEF}, \mathrm{ACGH}$, CDKL, all on the same side of $A B$.

On FH, within the square $\mathrm{AE}$, describe the square FHMN ; this is equal to the square on $\mathrm{CD}$.

Let NM, KL, produced if necessary, meet in $\mathrm{P}$.

Then $\mathrm{PE}$ is a square equal to the square on $\mathrm{AC}$.

And.PG is a square equal to the square on $\mathrm{DB}$.

The sum of the squares on $\mathrm{AD}, \mathrm{DB}$ is equal to the figures $\mathrm{AE}$ and $\mathrm{PG}$, that is to $\mathrm{AG}, \mathrm{PE}, \mathrm{FM}$, and $\mathrm{CK}$, that is to twice the sum of $\mathrm{AG}, \mathrm{CK}$, that is to twice the sum of the squares on $\mathrm{AC}$, CN.

\section{SCIENTIFIC SERIALS.}

American Meteorological Journal for November.-Prof. H. A. Hazen gives the results of three rather high balloon voyages in the United States, in which he took part. (I) June 25, 1886, at 7 h. $50 \mathrm{Om}$. a.m., a dense cloud was entered at Iooo feet, which seemed like a dry fog. The temperature from the earth up to more than half-way through the cloud hardly varied a degree, but after that it rose rapidly. There was a region of marked dampness at 7000 feet. The temperature at starting was $6 \mathrm{r}^{\circ} \cdot 3$, and at 9640 feet it had fallen to $8^{\circ}$; time, 9 h. $16 \mathrm{~m}$. (2) June II, 1887 , at $2 \mathrm{~h}$. $34 \mathrm{~m}$. p.m., temperature $90^{\circ} \cdot 6$. At 15,080 feet, it had fallen to $40^{\circ}$; time, $6 \mathrm{~h}$. $18 \mathrm{~m}$. p.m. Great dryness was experienced in the upper strata. There were two rather sharply defined layers of dampness, at 7500 feet and at 12,000 feet. (3) August 13,1887 , at $3 \mathrm{~h} .35 \mathrm{~m}$. p.m., temperature $75^{\circ} \cdot 8$. At 694 o feet it was $53^{\circ} \cdot 3$; time, $6 \mathrm{~h} .28 \mathrm{~m}$. p. m. The relative humidity fell to 8 per cent. - Meteorology at the French Association at Marseilles, by A. L. Rotch. Among the most interesting papers was one by M. Crova, upon the analysis of diffused light. Observations made at Montpellier at the zenith show the blue to be greatest in the early morning, and least about 2 p.m., and then increasing until towards evening. A cloudy sky also shows

NO. I I 56, vOL. 45] 